\title{
TESE AUTOBIOGRÁFICA: OS PROCEDIMENTOS PARA O CONSTRUCTO DO “EU” FONTE
}

\section{EDILSON FERNANDES DE SOUZA}

https:/ /orcid.org/0000-0002-8842-4304

Universidade Federal de Pernambuco

RESUMO Este artigo tem por objetivo apresentar uma sintese dos procedimentos metodológicos de uma tese para efeito de promoção na carreira de professor titular, denominada À luz do candeeiro e o constructo do "eu" fonte: educação pela arte, ciência e política. Assim, conto as estratégias desse estudo autobiográfico que mobilizou gravações de áudios, arquivos vivos, institucionais e da família, em virtude da minha trajetória ambientada no campo das artes, da ciência e política-institucional, que resulta na percepção do constructo do "eu" fonte, em função do autodistanciamento e o método da escrita de si. Palavras-chave: Autonarrativa. Arquivo pessoal. Constructo do "eu" fonte.

\section{ABSTRACT}

\section{AUTOBIOGRAPHIC THESIS: PROCEDURES FOR BUILDING THE "I" SOURCE}

This article aims to present a synthesis of the methodological procedures of a thesis for the promotion of the Full Professor's career, under the title In the light of the lamp and the construct of the "I" source: education through art, science and politics. Thus, I recount the strategies of this autobiographical study that mobilized audio recordings, living, institutional and family archives, due to my trajectory set in the field of arts, science and institutional politics, which results in the perception of the self construct. source, as a function of self-distancing and the method of writing itself.

Keywords: Self-narrative. Personal archive. "I" source constructo.

\section{RESUMEN}

\section{TESIS AUTOBIOGRÁFICA: PROCEDIMIENTOS PARA}

\section{CONSTRUIR LA FUENTE "YO"}

Este artículo tiene como objetivo presentar una síntesis de los procedimientos metodológicos de una tesis para promover la carrera de un profesor titular, llamado A la luz de la lámpara y la construcción de "yo" fuente: educación a través del arte, la ciencia y la política. Por lo tanto, cuento las estrategias de este estudio autobiográfico que 
movilizó grabaciones de audio, archivos vivos, institucionales y familiares, debido a mi trayectoria establecida en el campo de las artes, la ciencia y la política institucional, lo que resulta en la percepción de la autoconstrucción. fuente, en función de la distancia y el método de escritura en sí.

Palabras clave: Auto-narrativa. Archivo personal. Construcción fuente "yo".

Este artigo é um recorte dos procedimentos da tese em desenvolvimento intitulada $\grave{A}$ Luz do Candeeiro e o Constructo do "eu" Fonte: educação pela arte, ciência e política, a ser apresentada como requisito de ascensão à classe de professor titular na Universidades Federal de Pernambuco (UFPE). A decisão em escrever uma tese e não o memorial descritivo, amplamente exercitado para efeito dessa promoção na carreira, se deve ao fato de tentar mostrar a percepção que tenho dessa trajetória e como me constituí enquanto fonte numa determinada temporalidade autobiográfica.

Como esclarece Franklin (2009), normalmente, os docentes passam a escrever suas memórias acadêmicas a partir de um certo tempo de permanência numa instituição universitária, ou quando se aproximam da aposentadoria, já na consolidação de seu último estágio na carreira. Em seus estudos sobre autobiografia, a autora identifica um certo nivel de engajamento político por parte do narrador que, por vezes, reivindica mudanças institucionais e postulam um humanismo mais abrangente, no sentido de transformar as instituições num ambiente menos desigual nas relações de poder. Além disso, talvez se possa identificar nessas narrativas dos professores uma cultura acadêmica em processo de construção, e que bem pode representar os atores sociais que vivem em instituições universitárias (FRANKLIN, 2009).

Estudos como os de Franklin (2009) corroboram com a assertiva de que as narrativas de docentes podem construir um espaço de liberdade para tratar assuntos mais complexos do cotidiano universitário, como preconceito, racismo etc. Logo, "Uma das contendas centrais [de suas reflexões] é que as memórias fornecem insights cruciais sobre a política acadêmica porque, numa oferta de espaços que são mais flexiveis que as ofertadas pelas teorias podem [os professores] exibir contradições entre o pessoal e o político sem ter que conciliá-las" (FRANKLIN, 2009, p. 2, tradução nossa)!

No mesmo contexto das reflexões de Franklin (2009), a narrativa de si pode representar uma oportunidade crítica-reflexiva e ir mais além do que a formação profissional, conforme assinala Souza (2008). E, se for considerado que a vida é mais do que um currículo, a biografização, diz o autor, pode se expressar para além, ou conjuntamente, das questões da formação escolarizada, pode de certa forma, levantar a partir da memória, os aspectos identitários da profissão docente ou relacionadas às questões étnicas raciais, por exemplo. Aliás, segundo Souza (2008), o problema da identidade, bem como da alteridade também se colocam como um dos aspectos fundamentais na construção da narrativa de si. E essas preocupações são pontos de confluências de grupos de pesquisa que têm investido

1 "One of this book's central contentions is that memoirs afford crucial insights into the academy because, in offering spaces that are more musing and pliable than those afforded by theory, they can display contradictions be-tween the personal and political without having to reconcilie them" (FRANKLIN, 2009, p. 2). 
no processo de “investigação-formação docente", por meio da autobiografia.

0 que tem mobilizado os pesquisadores nessa vertente é o fato de que consideram o momento de formação inicial e continuada um dos elementos essenciais para a construção da identidade profissional, o que leva a hipótese de que o processo de formação deixa marcas fundamentais na história de vida dos indivíduos, na qual o método de narrar cumpre alguns papéis importantes, seja enquanto método de pesquisa, na construção de fontes, seja na autorreflexão sobre a própria formação em andamento (SOUZA, 2008).

Todavia, Silva (2015), ao analisar memoriais acadêmicos apresentados por docentes para ingresso por concurso ou para efeito de titulação, mostra a dificuldade encontrada por seus autores na perspectiva de falarem sobre si. Mas, em meio as dificuldades, é importante compreender a riqueza em termos de terminologias e abordagens com que os autores de suas narrativas encontram na distinção desse importante instrumento exigido por diferentes instituições. Para o autor, é impressionante como professores das mais diversas áreas do conhecimento "sofrem" da mesma angústia ao terem em algum momento de suas vidas profissionais-acadêmicas a necessidade institucional de falarem sobre suas realizações, seus feitos e efeitos consoantes a uma trajetória. Pelo que foi analisado por Silva (2015), as experiências relatadas variam consideravelmente o conteúdo, mas a forma direta, objetiva, portanto, descritiva, não muda.

0 autor considera que, com algumas exceções, ainda se encontram narrativas de si de uma maneira mais subjetiva, ou melhor, um alinhamento dos dados objetivos aos aspectos subjetivos da vida em família, da casa e outros eventos do convívio interpessoal. Mesmo não sendo o mais comum de se encontrar, esse tipo de narrativa de si expressa uma relação imbricada entre a profissão e a vida cotidiana, e ainda de acordo com Silva (2015), há um caminho bastante movediço ao tentar fugir das narrativas que se mostram mais objetivas, em que o autobiógrafo pode "[...] assumir litígios ou vindicações, e outros contrastes de luz e sombra, afirmação e negação, lembrança e esquecimento que tornam a vida mais do que um currículo" (SILVA, 2015, p. 133).

Os riscos apontados pelo autor tendem a movimentar o campo dos estudos autobiográficos, em que é possivel mapear diferentes perspectivas teóricas e metodológicas, aquilo que ele próprio chama de entradas e terminologias, para situar a fertilidade com que os memoriais têm sido produzidos no interior das intuições universitárias. Na perspectiva autobiográfica, portanto, é possível identificar, também, as formas e modelos de aprendizagens do próprio professor. Ou seja, como o professor aprendeu o que sabe, e de que maneira esse saber é transposto aos educandos. Com isso, estamos tratando da sociologia do conhecimento e das condições históricas em que o saber circula em um determinado ambiente social a partir de registros autobiográficos.

Nesse contexto, Passeggi, Souza e Vicentini (2011) situam as narrativas autobiográficas como parte importante do que chamam "virada biográfica em educação", no interior da qual emergem estudos preocupados em verificar "as razões da escolha profissional, as especificidades das diferentes fases da carreira docente, as relações de gênero no exercício do magistério, a construção da identidade docente, as relações entre a ação educativa e as políticas educacionais" (PASSEGGI; SOUZA e VICENTINI, 2011, p. 370).

Além desses aspectos, os autores apontam alguns avanços sobre esses estudos em países como na Alemanha, na França e anglo-saxões, e compreendem que nesses lugares, como 
também em Portugal e no Brasil, não se busca uma verdade do autobiógrafo, mas como esse "professor-narrador-autor" se situa no contexto histórico, ou de "como constrói a consciência histórica de si" (PASSEGGI; SOUZA e VICENTINI, 2011, p. 371). E no bojo desses estudos e suas diferentes abordagens, também se encontra a preocupação com as representações sociais do docente, bem como os aspectos de seu imaginário.

Estudos que apresentam essas características, quase sempre levam em consideração os aspectos socioeducacionais ou o ambiente em que o biografado recebeu suas marcas institucionais, que provavelmente têm impacto na formação do docente, na maneira como ele enxerga a vida e dilui seus percalços durante a trajetória. "Essa trajetória se inicia na graduação e se conclui pela ascensão ao nível de professor titular, considerado o ápice da carreira docente, na maioria das universidades brasileiras" (PASSEGGI; SOUZA e VICENTINI, 2011, p. 373).

Nesse contexto, resolvi escrever uma tese no método autobiográfico por considerar pelo menos dois aspectos da minha trajetória. Primeiro, oriundo das classes populares, ingressei aos 16 anos de idade no campo artístico da dança afro, atividade que me possibilitou pagar a faculdade e sustentar família. Essa minha atuação artística me fez enxergar a possibilidade de ingresso na vida acadêmica por meio de concurso público para professor auxiliar de ensino em uma universidade pública federal. Segundo, após 27 anos de atuação em uma instituição de ensino superior, chega o momento de decidir em acender na carreira por meio da apresentação de uma tese no método autobiográfico e defender a ideia de um constructo do "eu" fonte para corroborar com os avanços dos estudos dessa natureza. Sendo assim, este artigo tem por objetivo apresentar os procedimentos que utilizei para tratar dos episódios da minha trajetória de vida, considerando os aspectos subjetivos do processo narrativo, por meio de uma investigação científica.

\section{Os procedimentos da temporalidade autobiográfica e a composição das fontes}

Recorte temporal em pesquisas (auto)biográficas tem sido um elemento de razoável questionamento, por isso Goodson (2015) adverte para os procedimentos que possam demarcar metodologicamente as características desse tipo de estudo. Para o autor, a periodização pode ser compreendida em conformidade com a Escola dos Annales, numa perspectiva da longa duração, ou de característica que marcaram uma determinada geração entre os acontecimentos históricos, a exemplo da Segunda Guerra Mundial. Ou entre nós brasileiros, de uma forma muito específica, eu acrescentaria, a Ditadura Civil-Militar.

Além disso, a periodização pode ser demarcada pelos ciclos da vida, nascimento e morte, ou ainda, uma periodização delimitada a partir de como o próprio indivíduo enxerga os marcos de sua trajetória, "o tempo pessoal - o modo como cada pessoa delimita fases e desenvolve padrões de acordo com sonhos, objetivos ou imperativos pessoais ao longo do curso da vida" (GOODSON, 2015, p. 16). Dessa forma, conciliado com essas assertivas teóricas, comecei o estudo autobiográfico objeto dos procedimentos deste artigo pensando na seguinte questão: Qual a percepção que tenho da minha trajetória entre a escola, a vida acadêmica e o constructo do "eu" fonte (19742019)?

Considerando esses aspectos, 1974 é uma data muito especial. Aos nove anos, iniciei meu processo de alfabetização, com teste para a leitura das primeiras letras na cartilha do $A B C$, numa pequena escola domiciliar, e continuei 
os estudos passando por sete escolas públicas municipais e estaduais em diferentes cidades onde morei. Pelas memórias que trago para efeito deste artigo, posso garantir que o teste realizado naquela época tem impacto até hoje na minha emoção, e na minha maneira de enxergar as diferentes avaliações e exames necessários para chegar até esse estágio da classe mais alta de uma carreira, a de professor titular, numa das mais importantes universidades federais brasileiras. Assim, o constructo do "eu" fonte, objeto central da tese em desenvolvimento, é uma pequena e modesta homenagem à minha primeira professora quando de sua aplicação daquele tenso e necessário teste de alfabetização, a professora Dona Lilia.

Além dos episódios ancorados na escola e na vida acadêmica, fui durante muito tempo artista, profissionalizado por meio da técnica corporal da dança de matriz africana - dança afro -, e transmigrei de um campo artístico para o acadêmico, sublimando meus impulsos de artista na linguagem científica. Essa particularidade da transmigração de campo requer uma atenção bastante especial, principalmente porque foi no campo acadêmico onde pude experimentar várias tensões, inclusive disputas eleitorais para o cargo mais alto da instituição universitária, o de reitor. Então, 2019 é importante para a representação do fechamento de um ciclo político na instituição em que atuo, sobretudo, para o meu ato autobiográfico, conforme Calligaris (1998).

Todavia, mesmo sabendo que há curiosidade no desvelar das tramas que acompanham a narrativa de si, ou neste caso, a trama desvelada por um autobiógrafo amador, o propósito deste artigo é dizer dos procedimentos requeridos à contação da minha trajetória marcada por episódios escolares, acadêmicos, artísticos e políticos. Nesse contexto, ao decidir em escrever na perspectiva autobiográfica, fui em busca de meu pequeno acervo nas estantes de minha própria residência e depois o que dispunha no Laboratório de Sociologia do Esporte, vinculado ao Conselho Nacional de Desenvolvimento Científico e Tecnológico (CNPq), que coordeno há 20 anos na UFPE. Embora estando em dois ambientes, casa e instituição, o pequeno acervo na universidade foi adquirido com meus próprios recursos, certamente, do mesmo modo como fazem os colegas que estão lendo este artigo.

Em sua totalidade, tirando os livros emprestados, quase nunca devolvidos, o pequeno acervo é constituído de aproximadamente dois mil títulos, entre livros, dissertações e teses. Curiosamente, sobre o tema biografia, só encontrei apenas cinco livros, alguns capítulos e três teses que se servem rapidamente do assunto. Assim, fui tomado pelo desafio em levantar alguma literatura sobre a teoria que dá suporte a este estudo, e verificar as brechas que permitiam uma compreensão identitária acerca do tema. Desse modo, tentei costurar aspectos teóricos e elementos empíricos buscando sentido na autonarrativa e na documentação produzida em um determinado momento da minha trajetória.

O que estou chamando de autonarrativa é a fala gravada, compromissada na busca da memória, das minhas lembranças de fatos sobre minhas experiências de vida escolar e acadêmica, nas artes e na política, entrelaçadas com outros personagens das minhas relações interpessoais, profissionais etc. E diante da construção da autonarrativa, segui as reflexões de Marques e Satriano (2017), segundo as quais há necessidade de se escolher autores e teorias para que o pesquisador-narrador possa estabelecer um diálogo e fazer, na medida do possivel, a descrição e interpretação de suas emoções e motivações.

Considerando a razão narrativa, que segundo Delory-Momberger (2016) são episódios elencados pelo indivíduo no processo de re- 
cordação, comecei a gravar minhas memórias tendo como ponto de partida e motivação 1993, momento em que ingressei, por concurso público, como professor auxiliar de ensino na Universidade Federal de Uberlândia (UFU). Nessa minha fala, eu apresento o que consegui produzir do ponto de vista científico nessa primeira instituição em que atuei entre 1993 e 2000, ou seja, alguns resumos para congresso científico, a dissertação de mestrado e uma tese de doutorado, com suas particularidades. Cada uma a seu modo teve uma história à parte, sobretudo, porque se transformaram em publicações em formato de livros (SOUZA, Edilson, 2008; 2010).

O propósito não era fazer uma análise da dissertação e da tese, mas para situar os primeiros momentos da minha transmigração dos dois campos de interesse em que me encontrava naquela ocasião, entre a arte e a ciência. Penso que elas mesmas se explicam do ponto de vista do conteúdo, bem como a forma de escrita. Uma na primeira pessoa e a outra na terceira pessoa do singular, respectivamente, cujo conteúdo versa sobre afrodescendência, corporeidade, racismo e processos civilizacionais.

Considerados os primeiros áudios gravados num processo de recordação, os assuntos acabam se misturando, embora haja predominância de um tema em detrimento de outros em uma determinada experiência temporal. Esses aspectos são importantes na medida em que estamos ancorados nas reflexões de Halbwachs (1990) para quem "[...] não reconstituímos o quadro temporal senão depois que a lembrança foi restabelecida e então somos obrigados, a fim de localizar a data do acontecimento, dele examinar em detalhes todas as partes" (HALBWACHS, 1990, p. 101).

Seguindo essas orientações do autor, fui criando quadros sobre os episódios da trajetória e tentando reconstituir as temporalidades do que foi possivel percorrer até o presente momento. Com efeito, reafirmo por meio das recordações os principais ambientes por onde passei, resistindo, inclusive, ao tempo e transpondo os pequenos obstáculos encontrados por entre as linhas curvas e, às vezes, circulares. Essas lembranças chegam pelo exercício da autonarração e, também, por constante manuseio de diferentes documentos em arquivos institucionais, da minha família e os que constam do meu acervo pessoal.

Do ponto de vista institucional, copiei todo o conteúdo da minha Pasta de Assentamento Funcional arquivada no Setor de Registro e Movimentação, da Pró-reitora de Gestão de Pessoas e Qualidade de Vida (Progepe) da UFPE, da atual instituição em que trabalho. A pasta contém aproximadamente 198 documentos, que variam desde ficha de caráter pessoal (data de nascimento, filiação, local de lotação, estado civil) a portarias diversas de progressões, nomeações e exonerações; oficios dirigidos à instituição universitária para redistribuição; publicações do Diário Oficial da União (DOU), extrato de férias, fichas financeiras de vários anos, formulário de declaração de dependentes para imposto de renda, histórico de classificação na carreira do magistério superior, certidão de tempo de serviço etc.

Nesse contexto, fui buscar informações ao meu respeito em todos os lugares que tive notícia, inclusive, no Portal da Transparência, do governo federal. Entretanto, um dos arquivos institucionais de grande importância diz respeito às escolas onde estudei. Sempre tive a curiosidade de retornar a essas instituições. $\mathrm{Na}$ perspectiva das visitações, retornei após mais de 40 anos a esses ambientes aos quais sou muito grato, todas no estado de Pernambuco. Em um só dia, visitei quatro escolas, sendo: Escola de 10 Grau Professor Pedro Augusto Carneiro Leão, Escola Estadual de Beberibe, Escola Estadual Santo Inácio de Loyola e o 
prédio da Escola de 1o Grau Centro Educativo Operário Agamenon Magalhães, já extinta, e depois de alguns meses, visitei a primeira instituição em que estudei Escola Municipal de 1으 Grau Marechal Arthur da Costa e Silva.

Fui muito bem recebido em todas as escolas visitadas. Em uma delas, no Pedro Augusto Carneiro Leão, o diretor me levou à secretaria do colégio e pediu para que um dos funcionários fosse buscar a minha "Ficha", documentação de 1977. De forma rápida e inusitada, prontamente obtive em minhas mãos vestígios de um passado bastante importante em minha formação humana. 0 funcionário perguntou o meu nome completo, digitou no computador, retirou-se e voltou com uma caixa de plástico onde constavam várias fichas de pessoas que tinham o mesmo nome que eu, e uma delas era a documentação referente à minha passagem por três anos naquela escola. Dessa caixa também constava documentação da Escola de 1o Grau Centro Educativo Operário Agamenon Magalhães, especialmente o Certificado de Conclusão de Série, certamente, motivado pela transferência de instituição.

Considerando a emoção que me tomava conta, folheei rapidamente o que foi possivel, vi minha fotografia com 12 anos, mas fiquei sem saber o que fazer com aquele material. Até porque o técnico-administrativo, meu "xará", ao me entregar a pasta disse: "Aqui está toda a sua vida escolar. Toda sua vida está aqui". Então, eu disse que voltaria no outro dia para pegar uma cópia daqueles registros e doar alguns exemplares dos livros que eu havia escrito sobre alguns assuntos, como Ensaios da Civilização no Samba (SOUZA, 2018) e Memória da Copa do Mundo em Pernambuco (COSTA e SOUZA, 2018).

Além da visita à secretaria do colégio Pedro Augusto Carneiro Leão, percorri duas ou três salas de aula e fui apresentado aos estudantes. Uma das salas, acho que do 80 ano, ao ser apresentado à turma, embora não tenha conseguido falar absolutamente nada naquele momento, pela emoção que me tomava, fui aplaudido pela garotada. Em seguida fui até a quadra poliesportiva, a mesma onde tive a primeira aula de Educação Física. No dia seguinte, voltei à escola para buscar a cópia da minha Ficha Escolar, e a curiosidade era imensa em saber o que havia sobre minha estada naquele ambiente educacional. As notas, os conceitos, a matéria que "me saí melhor", o Português, a Matemática, História, enfim, um pouco do que havia deixado para trás e o que havia avançado entre os assuntos que trato atualmente.

Ah! Ao entrar nas escolas, meu sentimento era de respeito para com as pessoas que lá trabalhavam, inclusive a mesma sensação de quando era criança. A memória afetiva reagiu ao me aproximar dos ambientes administrativos, pois sempre tive respeito e, às vezes, a sensação de medo, especialmente em ambientes ocupados por pessoas que detinham o poder: diretores, supervisores etc.

Essa sensação de medo e respeito foi principalmente na escola em que fui matriculado na 5a série do 1o Grau, em 1977, no Pedro Augusto. Acho que a razão é óbvia, foi lá onde tive um pequeno embate com a diretora, Dona MJ, que me chamou a atenção por duas vezes no mesmo dia e me ameaçou de expulsão da escola. Não obstante essa sensação de medo, mesmo passado tanto tempo, e agora a lida era com um diretor, fiquei feliz em voltar a essas instituições. Assim, a principal mensagem que fica é a importância de um arquivo bem cuidado nas escolas. Digo isso porque meus documentos estão bem conservados e, provavelmente, há uma política de preservação desse acervo, bem como do estado geral dos ambientes onde estão guardados.

Os documentos encontrados foram bastante significativos e representativos de uma época escolar, seja de ordem pessoal, porque reve- 
lam uma parte da minha trajetória na educação formal, seja porque identificam, sobretudo, a política de escolarização a que uma sociedade está submetida. Digo isso porque além de verificar o que constam acerca dos meus registros, é possivel também, em certa medida, uma análise sobre a legislação que regia esse período, especialmente os pequenos "dribles" institucionais para ajustar a idade série dos estudantes. Pode revelar, ainda, os currículos exigidos e a formação esperada de meninos e meninas das classes populares, por exemplo.

Parece óbvio, mas é importante saber que todas essas escolas fazem parte de um sistema integrado, embora sejam intuições com muitas diferenças entre si, que possuem política de preservação e socialização de documentos próprios. Logo, a imagem que tive do Colégio Professor Pedro Augusto Carneiro Leão, a Escola Técnica Estadual Almirante Soares Dutra, bem como a Escola Epitácio Pessoa, a presteza com que recebi meus documentos, não foi a mesma com que obtive a documentação de outras escolas, inclusive, uma delas demorou seis meses.

Embora tenha recebido a Ata dos Resultados Finais, já na primeira visita no Colégio Almirante Soares Dutra, por exemplo, quando perguntei sobre a Ficha Escolar do ano de 1983, ou seja, alguns documentos relativos ao acompanhamento que a instituição fez ao meu respeito, recebi a resposta de que todo o material relacionado ao que precisava havia sido destruído pelos cupins. Mas, mesmo diante dessa situação, fui convidado a entrar na sala de apoio técnico e verificar em locus os gavetões de aço e os respectivos períodos aos quais a documentação se referia, neste caso, Atas - 1976 a 1983, e minha pasta: Enf/83, ou seja, concluintes do curso Auxiliar de Enfermagem de 1983.

O leitor deve saber que, por vezes, o método de pesquisa difere da forma de exposição de seus resultados, então, gostaria de registrar que a visitação às escolas foi feita uns nove meses depois de eu ter gravado as memórias, e isso pode ter afetado as minhas sensações. É como se eu estivesse ido às escolas, como fui, antes da presença física, o que pode ter mitigado as emoções a elas devotadas. É claro que isso é apenas uma percepção, mas ao recordar e depois visitar fisicamente as escolas, parecia que tudo estava exatamente no mesmo lugar, os móveis, o cheiro da cozinha e da merenda, as pessoas que lá trabalhavam, inclusive, a bendita diretora, Dona MJ.

Contudo, documentação sob a guarda das escolas pode evidenciar vários elementos importantes acerca do estudante. Notas, conceitos e matérias que clivaram o indivíduo durante um percurso escolar, fotografias oficiais para efeito de identificação do tempo da escola, endereços antigos do estudante, membro da família responsável pela matrícula em uma determinada instituição etc. Além disso, pode-se encontrar, ainda, evidências das características socioeconômicas e demográficas da família, seu tamanho e formas de parentesco, profissão e grau de escolaridade do pai e da mãe. Com esses dados, a escola e a própria rede de ensino podem traçar políticas específicas e mais eficazes no atendimento de seus estudantes.

Numa visitação ao arquivo e documentação escolar, ainda é possível identificar, que sendo de uma mesma rede, municipal ou estadual, as escolas se comunicam entre si e dão informes importantes de seus ritos, como, por exemplo, uma escola em que passei apenas seis meses, informa à escola subsequente que a avaliação na disciplina de Religião era conceito, onde o "B" equivaleria a nota 7,0 e, portanto, esse dado deveria ser levado em consideração para não me causar prejuízo.

Além disso, mesmo com essa informação, a escola que recebe o estudante poderia não ter 
a referida disciplina ou professor responsável, o mais provável. Na minha documentação escolar, por exemplo, na medida em que progrido às séries subsequentes percebo de maneira bastante expressiva a presença de conceitos em disciplinas julgadas importantes para a época, como "A Formação Especial" prevista na Resolução no 3/73 do Conselho Estadual de Educação, leia-se no estado de Pernambuco, ou, ainda, a Lei de no 5692/71 de Diretrizes e Bases da Educação, em seu Artigo 7ọ, que previa disciplinas como: Programa de Saúde, Educação Moral e Cívica, Educação Artística, Educação Física e Ensino Religioso.

Outro aspecto que gostaria de registrar, além da comunicação documental entre as escolas, mesmo numa rede estadual, como foi o caso, o corpo docente e administrativo tem uma relativa autonomia para avaliar seus estudantes. Além do mais, por alguma razão, seja pelo número de professores de determinada área, seja pela própria relação que aquela escola tem com os discentes, áreas de determinado conhecimento estão presentes em uma série e, em outra escola, essa mesma área sequer aparece como elemento da formação educacional. Essa constatação foi possível porque tenho em mãos a minha "Ficha Individual do Estudante", das escolas onde foi possivel a documentação, e mesmo não sendo objeto da pesquisa original, pude comparar os enunciados que evidenciam presenças e ausências de disciplinas e seus respectivos niveis de escolaridade.

Se as instituições onde estudei me permitem enxergar por meio de um arquivo os meus pequenos progressos educacionais: 5,0 e 9,0 em Português e 10 em Matemática, outro ambiente que não pode de maneira nenhuma ser negligenciado é o meu arquivo pessoal. Ou melhor, os papéis que se encontram em muitos lugares entre armários, estantes, gavetas etc. Minha pequena bagunça! Mas esse arquivo, como qualquer outro de uma família nuclear formada há pelo menos 23 anos, eu, minha esposa e mais cinco filhos, precisou ser visitado e a documentação perscrutada junto a outras da recordação.

No meu arquivo pessoal, pude encontrar uma infinidade de documentos, entre boletos bancários, extratos de cartões de crédito, já pagos, registros de casamento e nascimento, históricos escolares e de cursos de graduação e pós-graduação, declarações de bens, documentos de veículos antigos, certificados, declaração de conclusão de disciplinas cursadas na pós-graduação lato sensu, diplomas de todos os níveis de escolaridade, graduação, mestrado e doutorado; meu cartão de imunização, entre outros, crachá da Associação dos Cronistas Desportivos de Pernambuco, 2006 e 2010.

É importante registrar que apenas um ou outro documento desse arquivo foi utilizado na tese, até porque tive que separar o que havia de interesse para a composição das temáticas abordadas daquilo que servia apenas para recordação e futuros trabalhos. Então, tive que operar decisivamente na mudança de lugar dessa documentação, conforme Certeau (1998) e, de maneira mais drástica, a partir das reflexões de Saviani (2006) sobre a política de fontes, tive que fazer o descarte daquilo que, embora de interesse para uma história das minhas relações parentais, em nada acrescentaria ao projeto de tese, a não ser o de levantar a problemática dos arquivos pessoais e de família. Um fundo documental dessa natureza requer, sem sombra de dúvida, um tratamento especializado no contexto da política de fontes para diferentes perspectivas historiográficas, seja no campo econômico, da cultura da família, sua relação com a própria memória e a história da educação, por exemplo.

2 Refiro-me ao curso de Psicomotricidade e Pedagogia do Movimento Humano, realizado na Faculdade de Filosofia, Ciências e Letras de Arapongas-PR (Faficla), em 1991. 
Nesse contexto, penso que qualquer relato que possamos fazer em relação à nossa profissão ou outros interesses políticos etc., tem a ver, inevitavelmente, com a documentação encontrada nos nossos porões, nas bagunças deixadas entre caixas, sacolas, pastas, armários, gavetas e, eventualmente, em algumas estantes. Até porque ao vasculhar esses ambientes também veem à memória cenas, situações da vida, que talvez não viessem à tona se não houvesse esse movimento a partir de um pouco de contato com esses móveis e utensílios. Desse modo, tudo parece fazer recordar, trazer à memória as situações experimentadas por mim num simples gesto de aproximação desses objetos, inclusive, brinquedos esquecidos pelos filhos agora adultos.

É óbvio que um arquivo pessoal, como o meu que resolvi abrir e vasculhar, tem relevância na medida em que autobiógrafos precisam de algum documento que possam corroborar com algumas informações que complementam ideias ou possam puxar pela própria memória em decorrência do tempo. Uma carta de amigos, uma fotografia em família, um quadro sujo e desprezado. Ou seja, conforme pensa Halbwachs (1990), a memória coletiva e a conexão irremediável com os objetos distribuídos em um cômodo de uma casa, tudo pode fazer recordar.

Os objetos expostos em nossos lares trazem traços importantes da distinção social e, às vezes, também trazem à recordação um momento importante em que foi produzido ou adquirido, uma moda já antiga de seu uso, de sua relação com a sociedade mais ampla. Logo, num projeto autobiográfico como aqui estou a desenvolver, o pesquisador deve ficar atento para o fato de que o indivíduo recorda sua trajetória a partir e conjuntamente de um lugar e na sua relação com pessoas, objetos e imagens.

No fundo, qualquer acervo da família tem origem em tempos diferentes da própria exis- tência de algum de seus membros, filhos, entes que já se foram, outros que estão por vir, pedaços de uma família e complementos de outras, como, por exemplo, um dos cônjuge de casamentos anteriores, como foi o meu caso. Assim, encontrei documentos quando ainda era casado com a minha primeira esposa, documentos da nossa filha, por exemplo, e da dissolução de nossa união num acordo judicial. É que documentos provenientes do acervo de uma família podem ter inevitavelmente conexão com outras famílias, às vezes, desfeitas.

Em outros casos, filhos constituem suas próprias famílias nucleares e deixam por alguma razão documentos dos mais diversos com seus pais. Foi o que aconteceu comigo. Logo após o falecimento da minha mãe, encontrei documentos meus ou objetos relativos à minha vida quando morava em outros estados brasileiros. Entre esses objetos, estavam cinco cartas, uma de minhas carteiras de estudante de 1982 e fotografias de conteúdos variados.

Não obstante identificar a importância de se pensar numa política de fontes documentais provenientes de acervos da família, não pretendo aqui fazer uma discussão exaustiva pelas próprias limitações deste artigo, mas cabe, por enquanto, dizer que só apenas em 1990 esse tema de arquivo pessoal adquire status acadêmico-científico no rol das preocupações dos arquivistas. Segundo Britto e Corradi (2017), esse debruçar tardio sobre os arquivos pessoais talvez se deva à diversidade tipológica dos próprios documentos ali conservados.

De qualquer modo, é intrigante a complexidade documental que pode ser encontrada em um arquivo pessoal. Há de convir que um indivíduo tem relações estreitas com vários espectros da estrutura estatal, logo, podem ser encontrados nesse arquivo pessoal, não apenas documentos pessoais, mas, também, e em grande parte, documentos oficiais da relação do indivíduo com o Estado, seja em resposta 
ou em reclamação, ou na "outorga" do Estado em função de um diploma de uma universidade pública, por exemplo.

Ao fazer uso do meu arquivo pessoal, precisei separar o que era, efetivamente do titular do arquivo, ou seja, separar os meus próprios objetos dos demais objetos pertencentes a outros membros da minha família. Entretanto, boa parte dos documentos são mesmo produtos das minhas relações institucionais e interpessoais que envolvem outras pessoas que igualmente devem ter seus arquivos com a minha conexão. No entanto, mesmo verificando essa interrelação que os objetos têm e mantêm com outros indivíduos, seja da minha família ou de outros lugares, analisei apenas uma pequena parte daquilo que considerei essencial para a compreensão mais geral do estudo proposto, a tese a ser defendida para a promoção na carreira de professor titular e, inevitavelmente, foi isso que me levou a pensar na hipótese de trabalho do constructo do "eu" fonte, enquanto uma de minhas descobertas.

Entretanto, a utilização desse arquivo pessoal em trabalhos científicos, essa exposição de parte do acervo é também a conexão complementar das memórias, que a maioria das vezes a compreendemos apenas como os registros orais. Por isso tratei na tese de gravar a minha fala (arquivo vivo) que passará de agora em diante a fazer parte também de meu arquivo pessoal na relação de arquivos públicos, na medida em que o estudo original constará do repositório institucional da universidade em que atuo no momento.

Nesse contexto, ao gravar a autonarrativa, fui simultaneamente narrador e observador da narração. Sujeito e objeto desse tempo social e histórico da trajetória escolar e acadêmica que experimentei. E como não poderia deixar de identificar uma comunidade de destino para esta pesquisa, além de compreender que sou o próprio destino da minha fala, dos meus gestos e atitudes, as gravações originais, bem como as transcrições do meu discurso produzido para a tese é o Memorial Denis Bernardes, localizado na Biblioteca Central da UFPE, onde já se encontram um conjunto de materiais e objetos relacionados ao tempo em que me dediquei, por dez anos, a produção e apresentação de um programa de televisão da própria universidade.

As gravações do que chamo autonarrativa ocorreram em minha própria residência. Gravei as falas em várias etapas e dias diferentes, que ocorreram sempre entre $5 \mathrm{~h} 30$ e $7 \mathrm{~h}$ da manhã, na sala de tevê. A sala fica na "Pousadinha", próximo à piscina. A primeira ocorreu no último domingo de 2018, dia 30 de dezembro. Tive duas pequenas interrupções, a primeira, porque minha esposa precisava sair próximo às $7 \mathrm{~h}$ da manhã e pediu que eu fechasse o portão eletrônico, a uns 200 metros de distância, e a segunda interrupção foi em virtude do meu atrapalho com o equipamento, porque não consegui dar o "Ok", para continuar a gravação no aparelho celular.

A segunda gravação ocorreu no dia 31 de dezembro de 2018, num momento de muita apreensão, pois senti que deveria gravar antes do Ano Novo, talvez para deixar realmente para atrás algumas lembranças ou angústias que me afligiam durante aquele ano, sobretudo, a possibilidade de não concorrer à eleição para a reitoria em 2019, porque a situação da força política em que atuava naquele momento estava realmente muito tensa. A terceira gravação fiz no dia 2 de janeiro de 2019. Já havia me recuperado da ressaca, e acordei no mesmo horário de sempre, $5 \mathrm{~h}$ da manhã, tomei um café meio frio do dia anterior e fui até a sala de tevê, "a Pousadinha" para gravar no segundo dia do ano.

A quarta gravação foi realizada no dia 11 de janeiro de 2019, e decidi fazer esses registros 
após leitura do memorial de titularidade do professor Edson Hely Silva do Colégio de Aplicação (CAp) da UFPE, muito instigante a forma com que ele abordou alguns aspectos de sua vida escolar. Então, sua fala sobre esse tema me impulsionou também a tratar desse assunto. Além da inspiração vinda do professor Edson Silva, me senti obrigado em dar uma resposta e visibilidade às escolas por onde passei. Como não constava do roteiro original, precisei fazer um breve rascunho para guiar minimamente a minha fala, até porque os registros sobre as escolas por onde passei foram os mais emocionantes. Alguns momentos fiquei com a voz embargada por dois motivos: pelas lembranças das escolas e porque minha mãe já estava hospitalizada, com dificil recuperação.

Já a quinta gravação ocorreu no dia 12 de janeiro de 2019, e decidi fazer esse registro para complementar alguns elementos que faltaram da gravação anterior sobre a escola, e para escrever o último capítulo da tese, na verdade, o penúltimo, que trata sobre a política-institucional. Outra gravação foi realizada para um projeto da professora Inaldete Pinheiro de Andrade sobre Memórias da Negritude Pernambucana. Essa gravação ocorreu em 23 de janeiro de 2019, e foi seguramente a mais dificil porque a minha mãe havia sido sepultada três dias antes. Mas, pela disciplina de estudo como sempre tive durante a trajetória de vida, sabia que precisava gravar, transcrever e entregar à professora para a composição de seu projeto/livro. Entretanto, acabei utilizando todo o material inédito na tese porque o projeto inicial da professora foi cancelado por falta de financiamento.

Durante o processo de escrita do trabalho e revendo o que já havia produzido, senti a necessidade de fazer mais duas gravações para complementar alguns dados para efeito de compreensão de dois momentos importantes da trajetória. 0 primeiro, diz respeito às ques- tões políticas enfrentadas na UFU em que fiz o concurso para professor auxiliar de ensino, em 1993, e a outra gravação para responder ao que estava passando na instituição onde me encontro atualmente. Então, resolvi gravar no dia 19 de julho de 2019 e 24 de julho de 2019, os dois últimos áudios, para preencher algumas lacunas sobre a minha participação na política institucional.

Nesse contexto, foram oito áudios que serviram de suporte para o projeto geral da autobiografia. São as minhas memórias que ganharam força e serviram de esteio para a elaboração do trabalho escrito. Tecnicamente, o tempo de gravação e número de páginas quando de suas transcrições dependem da velocidade da voz, as emoções ali contidas e, obviamente, os detalhes que pretendi explicitar. Assim, percebi que gravar minhas recordações talvez não fosse mais necessário e, deveria, portanto, partir para a redação do texto final.

Ah! Como todos os dias, nesse horário, às 5h da manhã, também fui acompanhado pelo meu cachorro, já idoso, o Spike. Entre uma cochilada e outra, atento para o que eu dizia, às vezes resmungando, fazendo "pum", e às vezes roncando, estava por perto. Muito bom ele estar por ali, principalmente porque a sala que elegi como "estúdio" fica na parte de fora da casa, a "Pousadinha", uns 31 metros da casa principal. É sempre bom mesmo ter o pulguento por perto, mesmo sonolento.

Essa atitude de gravar praticamente em cinco ou seis dias seguidos, e o espaçamento de alguns meses, com esse tempo razoável de explicitação da narrativa, me faz lembrar as experiências de que "os biografados são capazes de narrar suas vidas durante muito tempo - horas -, frequentemente sem vacilações, apesar de lhes ser pedido que façam de um modo muito geral" (ROSENTHAL, 2006, p. 195). Nessas situações de contar a história, o tempo é precioso, o tempo leva aos desfechos das 
experiências, porque abrimos e fechamos cenas, que aparentemente estão desconexas por ocorrem em momentos diferentes, mas estão irremediavelmente conectadas, mesmo com o espaçamento da lembrança, e da própria experiência física.

É claro que nesta investigação científica me impus um roteiro, mas o fato concreto é que, se o projeto trata de um outro indivíduo ou de nós mesmos, temos razoável interesse na história a ser contada. E quando falamos e ouvimos sobre nós mesmos dá uma agradável sensação de dever cumprido, seja por conta da vida enquanto experiência, e o relato registrado tenta confirmar isso, seja pelo compromisso com a pesquisa, razão deste ritual. De qualquer modo, gravei as narrativas com o roteiro nas mãos. Sempre falei para um outro, talvez para o meu ego, ou para o Spike. Ao escutar as gravações, percebi que havia lapsos de memória na narrativa. Datas, nomes de pessoas e alguns cenários, pareceram se impor pela fuga das lembranças. Por alguma razão falhei ao tentar lembrar. Decidi, então, que depois das transcrições e ler o documento deveria completar a retórica, e deixar mais claro o que queria realmente dizer com as palavras gravadas, na verdade, esquecidas.

O cenário das gravações, a "Pousadinha", fica próximo à piscina, ao terraço e a cozinha gourmet. É um cômodo de aproximadamente $27 \mathrm{~m}^{2}$, porta e três janelas de madeira. No seu interior, encontram-se uma estante com 350 títulos, entre livros, dissertações e teses, dois sofás velhos, um aparelho de televisão sobre o raque, um tapete de palha, onde o Spike fica deitado, uma cadeira de plástico, duas quartinhas de enfeite de argila, a mesa e ferro de passar roupa, um pufe preto e branco, e vários enfeites de cerâmica e madeira, alguns desses provenientes da Guiné-Bissau-África. Ah! E um ventilador de mesa, porque depois do meio dia, o calor é insuportável, mesmo com a piscina de frente e um pé de manga espada ao lado. Assim, enquanto síntese da dinâmica das gravações e transcrições, segue o Quadro 1.

Quadro 1 - Aspectos gerais dos áudios da pesquisa.

\begin{tabular}{|l|c|c|c|c|}
\hline Título da Gravação & $\begin{array}{c}\text { Tempo de } \\
\text { Gravação em } \\
\text { Minutos }\end{array}$ & Local da Gravação & $\begin{array}{c}\text { Data da } \\
\text { Gravação }\end{array}$ & Páginas \\
\hline Primeira gravação & $52: 08,16$ & Residência/Pousadinha & $30 / 12 / 2018$ & 10 \\
\hline Biografia, fala 2 & $44: 11,34$ & Residência/Pousadinha & $31 / 12 / 2018$ & 9 \\
\hline Biografia, fala 3 & $53: 05,47$ & Residência/Pousadinha & $02 / 01 / 2019$ & 11 \\
\hline Escola gravação 1 & $55: 18,71$ & Residência/Pousadinha & $11 / 01 / 2019$ & 11 \\
\hline Escola e política & $41: 13,73$ & Residência/Pousadinha & $12 / 01 / 2019$ & 8 \\
\hline Memórias da Negritude & $42: 25,62$ & Residência/Pousadinha & $23 / 01 / 2019$ & 7 \\
\hline Largaram a mão & $13: 57,98$ & Residência/Pousadinha & $19 / 07 / 2019$ & 2 \\
\hline Eleição/Diretor/Reitor & $08: 87,00$ & Residência/Pousadinha & $24 / 07 / 2019$ & 1,5 \\
\hline
\end{tabular}

Fonte: elaborado pelo Autor, 2019

Conforme pode ser visto no Quadro 1, foram oito gravações que renderam um tempo aproximado de mais de cinco horas, resultan- do, basicamente, cinquenta e nove páginas e meia. É importante observar, ainda, que essa paginação se refere a parágrafo único e espaço 
simples no Times New Roman, fonte 12. Após transcrição, fui reelaborando seu conteúdo e editando algumas palavras ou frases inteiras para melhor compreensão do contexto da recordação, bem como corrigir, após verificação, datas, nomes de personagens, cenários dos episódios etc.

Mesmo arcando com as responsabilidades éticas que envolvem um projeto autobiográfico, porque você sempre fala de si em relação a um outro, é praticamente impossivel a identificação na tese dos trechos extraídos das gravações e o que consegui elaborar a partir de uma vasta documentação iconográfica e impressa. Por enquanto, é importante que o leitor tenha em mente que a base fundamental do que está escrito no texto final, pelo menos $30 \%$, de um total de mais de 400 páginas em desenvolvimento, foi produzido a partir das gravações. Contudo, para efeito de identificação, quando a referência for extraída do Currículo Lattes, biografia secundária, aparecerá as iniciais do meu nome e a palavra "Lattes", precedido do ano e páginas.

Do mesmo modo, ao ler o meu sobrenome, precedido do ano e, às vezes, seguido por letras para diferenciação, posso estar me referindo algumas das minhas publicações, que a partir de citações diretas ou indiretas chamarei a atenção para alguma informação relevante enquanto autor. De outro modo, ainda considerando minhas próprias citações, por exigência, quando o leitor estiver diante do meu sobrenome e nome (SOUZA EDILSON, 2009), diz respeito às referências ao depoimento que concedi ao Laboratório de História Oral e da Imagem (LAHOI) da UFPE. Essa entrevista foi concedida em 22 de junho de 2009 e teve a duração de aproximadamente três horas.

Embora eu tenha utilizado parte significativa desse material por se tratar de conteúdo da minha história de vida, não expus no Quadro 1 porque não possui as mesmas características dos áudios que produzi especificamente para o objeto da tese. Então, a soma total de áudios para a modelagem deste estudo é de aproximadamente oito horas, e a paginação das transcrições do referido laboratório renderam aproximadamente 72 páginas, já considerando as intervenções dos entrevistadores, professora Isabel Guillen e Ivaldo Marciano.

Nesse contexto, para a recordação e gravação, mantive os nomes reais dos personagens, mas no processo de escrita do enredo, no texto final, tomei a iniciativa de resguardar alguns personagens que entraram e saíram da minha trajetória, principalmente de forma positiva em um determinado momento e negativa no outro. Logo, ao serem citados como membros integrantes desse campo, as referências que por ventura faço a eles textualmente, serão grafadas por nomes abreviados e fictícios.

Percebo que na autonarrativa, entre uma lembrança e outra, esquecimento e outro, preservei alguns personagens que fazem parte da trajetória, às vezes, omitindo algumas informações relevantes sobre eles, inclusive a minha percepção acerca de sua integridade ética e moral. Em alguns momentos, omiti informações relacionadas às faltas graves em que essas pessoas me atingiram frontalmente, pelo menos é a minha percepção. Em outros, ressaltei algumas de suas qualidades. De qualquer modo, segui as orientações de Eakin (2019) quando trata das regras da autobiografia e "do direito à privacidade" (p. 46).

Numa autonarrativa como a que me submeti, interdita-se ou libera-se informações. Isso posto, a autobiografia tem entre outras, a função relacional do sujeito objeto. Quem se submete a esse processo autobiográfico, sabe que não se trata de associação livre, como a de um tratamento psicanalítico, ou de um registro psicológico, do ponto de vista da saúde mental. Trata-se, portanto, de um ponto de vista histórico-social, onde os personagens entram 
e saem da história com certa possibilidade de atuação mais positiva, ou mais negativa na trama, ao modo das escolhas do autobiógrafo.

Há na contação da trama não apenas um resguardo do outro. Então, nessa minha autobiografia, faço o registro de pessoas que julguei mais importantes para aquele momento que está sendo descrito, aquela cena, aquela passagem, aquele período curto da história. Por outro lado, mesmo chamando a atenção para certos personagens, fazendo seu registro na trajetória, lembrei de outros personagens que também participaram do mesmo momento, da mesma cena, mas não registrei, ou não registrei devidamente, fiz uma rápida seleção de quem entrava ou não na história.

A memória realmente é seletiva, e a autobiografia quando submetida ao processo da recordação também tem esse caráter de conceder ou não conceder o registro de pessoas ou cenas. As escolhas que você faz desse registro. Um caráter de interditar ou permitir a participação de outros agentes sociais nessa trajetória. Foi assim que procedi, e só tomei ciência desses aspectos quando resolvi escutar as gravações. Outro aspecto, diz respeito, de fato, ao esquecimento daquele tempo histórico, daquele cenário. Nome de pessoas, objetos, lugares, ou situações que foram vividas aparecem na narrativa às vezes de forma parcial. E só no momento seguinte que fui escutar as gravações, o que foi dito, acabei lembrando que de fato o nome exato das pessoas não eram aqueles. As cenas ocorreram, mas ocorreram em outro momento ou lugar. São as imperfeições do método.

Destarte, o leitor pode estar se perguntando onde estaria a verdade nesse estudo, uma vez que se trata de uma investigação científica. Então, leitor, todos sabemos que não existe a verdade absoluta. Mas, se há alguma nesse trabalho, ela existe na própria contação das falhas, dos ditos e interditos sobre temas, ce- nários e personagens. Os equívocos e omissões próprias de uma narrativa de si. Entretanto, esses aspectos são fundamentais no rigor do método aqui empregado, considerando o que Velandia Mora (2010) trata acerca da reflexividade na autoetnografia, ou conforme Eakin (2019) ainda ao tratar do direito à privacidade.

De qualquer maneira, diante desses elementos técnicos de exposição e registro da trajetória, fui levado a fazer alguns consertos na narrativa. Um processo técnico, uma edição da fala. A edição da narrativa, na qual fiz alguns complementos, ajustes para que aquele tempo histórico estivesse condizente com a cena descrita, ou a cena descrita estivesse condizente com aqueles personagens e tempo histórico. Às vezes, os fatos são narrados fora da sequência com que ocorreram, e quando relatados oralmente têm um certo sentido, mas, quando transcritos, precisam ser realinhados na representação gráfica.

Nesse processo de edição, foi possivel cortar frases e palavras repetidas, ao mesmo tempo preencher as lacunas e acrescentar palavras, frases e, às vezes, ideias inteiras para realçar a lembrança. Como o relato gravado e transcrito ocorreu num determinado momento e a reescrita em outros, foram imprimidas várias emoções no texto que chegará ao leitor. Digo isso porque nesse processo de edição da fala eu estava realmente vivendo outro momento de quase perda e a perda propriamente dita da minha mãe. Por isso, o leitor pode deparar com situações que mais se parecem com "fita travada" de áudio ou imagem, em que num determinado tópico há a morte, e depois seu sofrimento na Unidade de Terapia Intensiva (UTI). Coisa inversa da vida e de uma transcrição sucedida.

De modo que essas interdições, essas idas e vindas, esses quase contratempos da narrativa são interessantes porque mostram as nuances. Mostram essas ondas de memória, 
que chegam e você libera para a exposição ou registro. Não que você queira esquecer propositalmente, mas é o fato de não querer registrar, pelo menos naquele momento. Logo, a autobiografia é uma construção política, na medida em que você decide o que quer conectar com a história, com a trajetória, o que você deseja influenciar e como pretende influenciar a partir dos registros da fala.

Contudo, é entre uma tomada de decisão e outra, entre um posicionamento político e outro que fui construindo e reconstruindo cenas, imagens, cheiros e gostos. Fui personificando e atribuindo sentido ao que está sendo dito e interditado simultaneamente. E esse trabatho é fundamental para a construção de um "todo da trajetória" trazido à lembrança, bem como a concretização de um desfecho hipotético, ou seja, a verificação instantânea de onde cheguei com aquelas palavras e frases ditas. Parafraseando Goodson (2015), aqui possuí a informação privilegiada, controlei os testemunhos e o relatório final da investigação. $E$ tive também o cuidado, conforme orientação do autor, de garantir o "fluxo" e "focagem" da narração, a "abrangência" e a "profundidade", o que pode ser compreendido a partir do diagrama a seguir:

Figura 1 - Diagrama do Constructo.

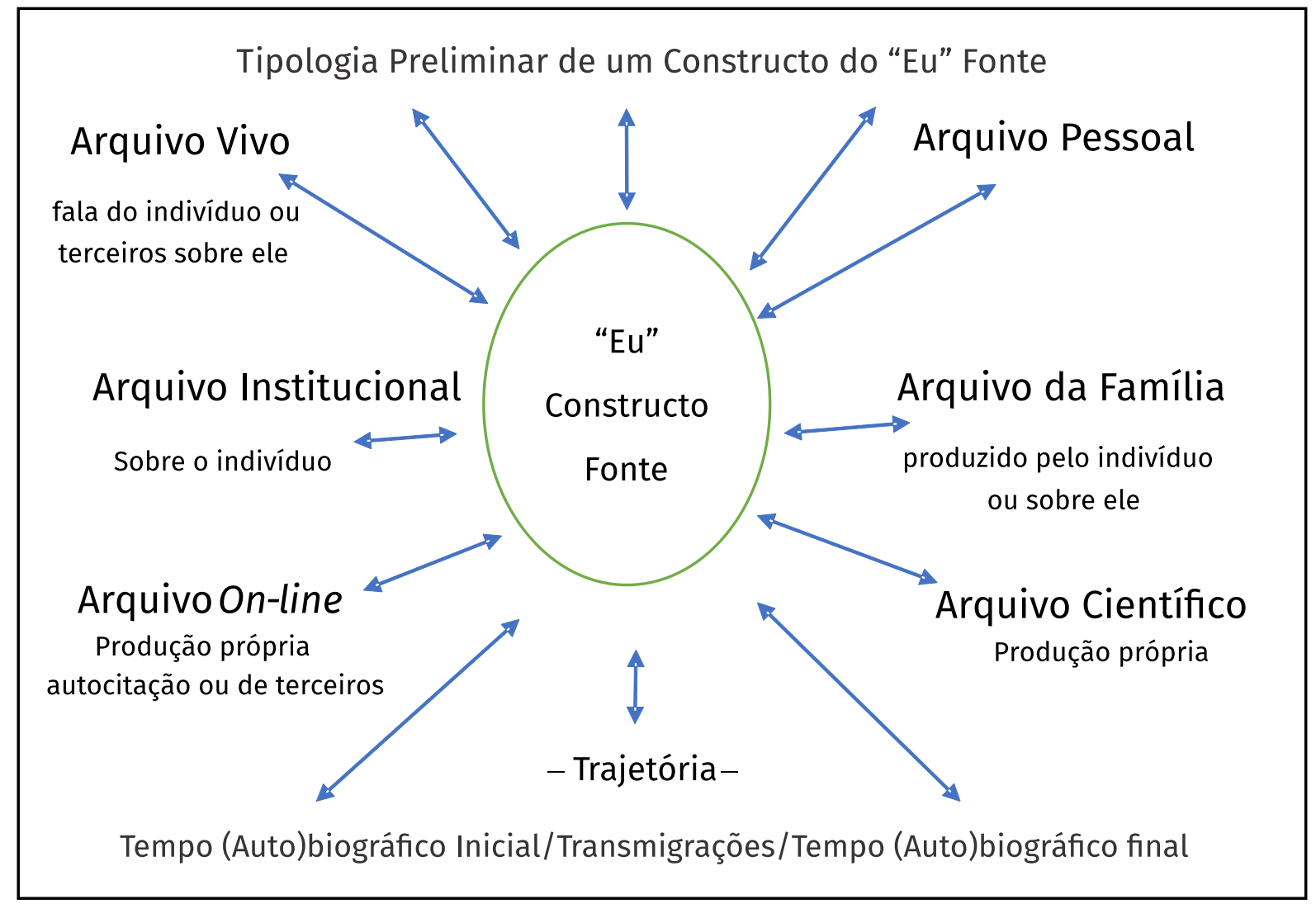

Fonte: elaborado pelo Autor, 2019.

Como pode ser visto, são seis arquivos distribuídos no diagrama, que representam a dispersão da evidência de uma trajetória. Como é autoexplicativo, logo é possivel verificar que as fontes são provenientes dos arquivos vivos (fala do próprio (auto)biografado ou de pessoas próximas); arquivo pessoal; arquivo da família ou amigos, arquivo das instituições por onde o autobiografado trabalhou ou manteve alguma relação profissional, bem como o arquivo on-line, das evidências encontradas nos periódicos que citam o (auto)biografado em seu campo acadêmicocientífico, e, por último, o arquivo científico 
(própria produção, como artigos, livros, dissertação e tese).

No centro do diagrama, está a própria fonte que impulsiona as evidências, e sua trajetória é representada pelo tempo (auto)biográfico inicial - os primeiros episódios -, depois, as transmigrações, que demarcam as mudanças de território, de trajetória e enfoque acadêmico-científico, e, finalmente, o tempo (auto)biográfico final, a delimitação que encerra a trama tecida.

A partir desse diagrama, diante do conjunto documental e na construção das diferentes fontes, procedi a análise seguindo as orientações de Aróstegui (2006) com vista à duas categorias, sendo: a fiabilidade e a adequação. Para esse autor, a fiabilidade diz respeito à originalidade da fonte, sua datação, sua história, autoria e condições sociais de sua produção, e eu acrescentaria constituição do acervo e conservação. Logo, o que foi aqui constituído para efeito de análise documental está em conformidade com a originalidade exigida pelo autor, sobretudo, quando a minha consciência de pesquisador permite identificar não apenas a natureza das fontes, mas, especialmente a relação dessa construção de fontes e minha relação enquanto sujeito e objeto de pesquisa.

Já a adequação é abundância documental, a quantidade e a qualidade da fonte capaz de responder a números razoáveis de perguntas na representação de um espaço-temporal. Nesse sentido, a ideia central de Aróstegui (2006) diz respeito a organização documental e sua constituição para análise. Neste estudo, a adequação, essa abrangência e massa documental foi extraída de vários arquivos que acabaram impactando numa forma bem específica de informação acerca da minha trajetória, resultando, inclusive, na afirmação da hipótese formulada de um constructo do "eu" fonte.
Pensando ainda na adequação, como dito anteriormente, eu trouxe para a análise as gravações realizadas em diferentes momentos da construção da tese, bem como na concessão de depoimento para um projeto de história oral já mencionado e, na medida do possivel, submeti os meus ditos; as falas, à análise documental semelhante ao que está previsto por Aróstegui (2006). Assim, o estudo está baseado num conjunto de procedimentos puxados pela memória num processo de aglutinação da própria percepção que tenho da minha trajetória. E o diagrama em questão mostra a mobilização feita na perspectiva de uma versão preliminar do constructo do "eu" fonte, ou seja, os arquivos trazidos à lembrança de um itinerário, em que construo as fontes e sou por elas constituído.

\section{Considerações finais}

Neste artigo, procurei apresentar uma síntese acerca dos procedimentos utilizados na construção de uma tese autobiográfica para efeito de promoção na carreira docente, e espero poder contribuir com outros profissionais que, por meio de seu árduo trabalho na universidade, possam também se expressar a partir dos impulsos de uma escrita de sua trajetória. Além disso, a tentativa aqui foi a de responder aos questionamentos de Marques e Satriano (2017), se seria possivel considerar válida para as Ciências Humanas e Sociais uma narrativa ou autobiografia do próprio pesquisador enquanto seu objeto de investigação. E, para tanto, explicitar os procedimentos pelos quais alcei para narrar as tramas da minha vida, parece ser uma das melhores respostas para corroborar com alguns pesquisadores que se encontram na mesma encruzilhada em que estive durante alguns momentos para a tomada de decisão dos meus atos autobiográficos. 
É óbvio que as autoras fazem esses questionamentos pensando nos pesquisadores dessas áreas do conhecimento que, ao investigarem a sociedade do seu tempo, estão em última instância investigando a si mesmos, como um dos seus membros. Não obstante, tem crescido o número de trabalhos que procuram o método que ancora nas narrativas de si, seja por meio de memorial descritivo, como tem feito professores universitários para atender a diferentes propósitos acadêmicos, seja por tese autobiográfica, como o fiz enquanto desafio. Entretanto, seja como for, os estudos desse método já encontram consolidados na ampla bibliografia disponivel.

Embora o meu esforço, neste momento, seja o de reafirmar que se trata aqui de uma investigação científica e não de um gênero textual da literatura, vejo que os aspectos procedimentais aqui tratados deixarão algumas lacunas. $\mathrm{E}$ ainda que tenham sido reparadas no decorrer da narrativa, não conseguirei eliminar o todo das minhas subjetividades, até porque um estudo como está proposto tenta verificar exatamente os aspectos subjetivos do pesquisador-narrador de sua trajetória. Desse modo, outros estudos podem ser acrescidos a essa minha experiência, especialmente no que diz respeito à mobilização de diferentes arquivos que apontem evidências significativas de uma trajetória de um determinado pesquisador-narrador-autobiógrafo.

Por fim, especial atenção deve ser dada ao que chamo de constructo do "eu" fonte. A percepção que tenho do que foi produzido e disperso durante a minha trajetória, e que por meio desse meu processo autonarrativo, e a mobilização de diferentes arquivos o demostram, consegui encontrar uma certa unidade da dispersão. Assim, talvez seja possível a reaplicação desse construto por outros pesquisadores para ampliar o leque de procedimentos e aperfeiçoar a condição do próprio método (auto)biográfico.

\section{Referências}

ARÓSTEGUI, Júlio. A Pesquisa histórica: teoria e método. Trad. Andréa Dora. Bauru, SP: Edusc, 2006.

BRITTO, Augusto César Luiz e CORRADI, Analaura. Considerações teóricas e conceituais sobre arquivos pessoais. PontodeAcesso, v. 11, no 3, p. 148-169, dez. 2017. Disponível em: https://portalseer.ufba. br/index.php/revistaici/article/view/22745/15505 Acesso em: 23 ago. 2019.

CALLIGARIS, Contardo. Verdades de autobiografias e diários íntimos. Revista Estudos Históricos, v. 11, no 21. p. 44-58. 1998. Disponível em: http:// bibliotecadigital.fgv.br/ojs/index.php/reh/article/view/2071. Acesso: em 10 mar. 2019.

CERTEAU, Michel. A invenção do cotidiano: artes de fazer. 3a ed. Trad. Ephraim Ferreira Alves. Petrópolis: Editora Vozes, 1998.

DELORY-MOMBERGER, Christine. A pesquisa biográfica ou a construção compartilhada de um saber do singular. Revista Brasileira de Pesquisa (Auto) Biográfica, Salvador, v. no 1, p. 133-147, jan./abr. 2016. Disponível em: https://www.revistas.uneb.br/index. php/rbpab/article/view/2526/1711. Acesso em: 2 ago. 2019.

EAKIN, Paul John. Vivendo autobiograficamente: a construção da identidade na narrativa. Tradução Ricardo Santhiago. São Paulo: Letra e Voz, 2019.

FRANKLIN, Cynthia G. Academic lives: memoir, cultural theory, and the university today. The University of Georgia Press Athens \& London, 2009.

GOODSON, Ivor F. Narrativas em Educação: a vida e a voz dos professores. Trad. André Pacheco. Porto -Portugal: Porto Editora, 2015.

HALBWACHS, Maurice. A memória coletiva. São Paulo: Vértice, Editora Revista dos Tribunais, 1990.

MAUAD, Ana Maria. Através da imagem: fotografia e história interfaces. Tempo, Rio de Janeiro, v. 1, n으 2, p. 73-98, 1996. Disponivel em http://www.historia.uff.br/tempo/artigos_dossie/artg2-4.pdf. Acesso em: 9 out. 2019.

MARQUES, Valéria, SATRIANO, Cecília. Narrativa au- 
tobiográfica do próprio pesquisador como fonte e ferramenta de pesquisa. Linhas Críticas, Brasília-DF, v. 23, n. 51. p. 369-386, jun./set. 2017. Disponivel em: https://www.redalyc.org/pdf/1935/193554180008. Acesso em: 14 out. 2019.

PASSEGGI, Maria da Conceição; SOUZA, Elizeu Clementino de, VICENTINI, Paula Perin. Entre a via e a formação: pesquisa (auto)biográfica, docência e profissionalização. Educação em Revista, Belo Horizonte, v. 27, no 01, p. 369-386. abr. 2011.

ROSENTHAL, Gabriele. A Estrutura e a Gestalt das autobiografias e suas consequências metodológicas. In: AMADO, Janaina e FERREIRA, Marieta de Moraes. (Orgs.). Usos e abusos da história oral. 8 ed. Rio de Janeiro: Editora FGV, 2006.

SAVIANI, Dermeval. Breves considerações sobre fontes para a história da educação. Revista HISTEDBR On-line. Campinas, n. especial, p. 28-35, ago. 2006. Disponivel em: http://www.histedbr.fe.unicamp.br/ revista/edicoes/22e/art5_22e.pdf. Acesso em: 14 ago. 2019.

SOUZA, Edilson Fernandes de. Representações de afro-brasileiros: depoimentos de dançarinos-atores. Recife; Editora Universitária da UFPE, 2008.

SOUZA, Edilson Fernandes de. Entre o fogo e o vento: as práticas de batuques e o controle das emoções. 3a ed. Recife; Editora Universitária da UFPE, 2010.

SOUZA, Edilson Fernandes de. Ensaios da civilização no samba. Curitiba: Editora CRV, 2018.

COSTA, Marcos André Nunes, SOUZA, Edilson Fernandes de. Memória da copa do mundo em Pernambuco: os documentos e o monumento. Recife; CEPE, 2018.

SILVA, Wilton C. L. A vida, a obra, o que fala, o que sobra: memorial acadêmico, direitos e obrigações da escrita. Revista Tempo e Argumento, Florianópolis, v. 7, no 15, p. 103-136. maio/ago. 2015.

SOUZA, Elizeu Clementino de. (Auto)Biografia, identidades e alteridade: modos de narração, escritas de si e práticas de formação na pós-graduação. Revista Fórum Identidades, ano 2, v. 4, p. 37-50, jul./ dez. 2008. Disponivel em https://seer.ufs.br/index. php/forumidentidades/article/view/1808. Acesso em: 7 ago. 2019.

VELANDIA MORA, Manuel Antonio. De la autobiografia a la autoetnografia como herramienta para el estúdio de si mesmo. Universidad del País Vasco, España, 2010.

Recebido em: 27.12.2019 Aprovado em: 01.06.2020 Revisado em: 03.06.2020

Edilson Fernandes de Souza é pós-doutor em Sociologia pela Universidade do Porto-Portugal. Doutor em Educação Física/Estudos do Lazer pela Universidade Estadual de Campinas (Unicamp). Docente do Programa de Pós-graduação em Educação/Núcleo de Teoria e História e do Mestrado em Gerontologia/Envelhecimento, Cultura e Sociedade, ambos da Universidade Federal de Pernambuco (UFPE). É membro do Grupo de Pesquisa Processos Civilizadores, vinculado ao Conselho Nacional de Desenvolvimento Científico e Tecnológico (CNPq).E-mail: edilson.souza@ufpe.br 